\title{
Structural analysis of the Babesia microti thioredoxin reductase: a potential drug target for babesiosis treatment.
}

\author{
Neelima Arora $^{1 *}$, Amit Kumar Banerjee ${ }^{2}$, Mangamoori Lakshmi Narasu1 \\ ${ }^{1}$ Centre for Biotechnology (CBT), Institute of Science and Technology (Autonomous), Jawaharlal Nehru Technological \\ University Hyderabad, Kukatpally, Hyderabad, Telangana, India \\ ${ }^{2}$ Biology Division, CSIR-Indian Institute of Chemical Technology, Uppal Road, Tarnaka, Hyderabad, Telangana, India
}

\begin{abstract}
Babesia microti, the causative agent of human babesiosis which was endemic in United States and parts of Europe with sporadic cases in other regions is expanding its geographical range. Being a common transfusion threat, Babesia has become a cause of concern in researchers and epidemiologists. Human babesiosis is now recognized as an emerging disease and gains more attention now than ever before. Thioredoxin reductase, a promising drug target in apicomplexan parasite has been validated in several species. This study focused on in-silico analysis of physicochemical properties, functional and structural aspects of thioredoxin reductase of $\boldsymbol{B}$. microti. Comparative modeling approach was adopted for developing the three dimensional structural model of Thioredoxin reductase of Babesia microti. The model developed was found to be of reasonably good stereo-chemical quality by structure validation servers. This study will provide valuable insights about the function and structure of the enzyme thioredoxin reductase of $B$. microti and aid in developing effective chemotherapeutic agents for control and treatment of Babesia.
\end{abstract}

Keywords: Babesia microti, Babesiosis, Thioredoxin reductase.

Accepted on April 28, 2018

\section{Introduction}

Babesiosis in humans and animals is caused by apicomplexan zoonotic hematotropic parasites of the genus Babesia transmitted by ticks. Babesia is quite ubiquitous in nature with a wide range. Babesia is one of the most common blood parasites of mammals. Babesiosis is one of the most common infections of animals and causes profound economic, medical and veterinary impact globally. After years of being recognized as major pathogen in cattle causing huge economic losses, babesiosis has recently gained recognition as an important pathogen of human [1]. First case of babesiosis was reported in Croatia in 1957 [2]. Babesiosis caused by the B. microti in human in United States was first documented in 1969 [3].

Out of more than 100 known species of Babesia, only a fraction cause human babesiosis. Among these, genetically distinct Babesia microti is the predominant species in US and major culprit responsible for causing human babesiosis. The spectrum of Babesiosis ranges from asymptomatic to severe malaria-like symptoms including chills, sweats, headache, arthralgia, myalgia, anorexia, cough and occasionally causing deaths in humans. Babesia disease cycle progresses in two hosts involving black legged deer ticks of belonging to Ixodes genus as definite host and a vertebrate intermediate host primarily. Peromyscus leucopus while humans are accidental hosts or dead-end hosts who acquire the infection with the bite of infected ticks. The disease is tightening its grip in many states of United States as well as other parts of the world including Europe and a few Asian countries. Co-morbidity of babesiosis with Lyme disease and possibility of underreporting in asymptomatic patients often compounds the situation. The fact that Babesiosis can be transmitted congenitally as well as through blood transfusion and is difficult to diagnose makes the situation worse [4,5]. Babesia can even survive for prolonged period in blood storage conditions. Babesiosis has emerged as a major transfusion transmitted threat of the recent times [5]. Babesia remains understudied unlike another apicomplexan parasite Plasmodium and Toxoplasma. Owing to increased number of incidences over past few years, human babesiosis is now classified as emerging disease [6]. CDC has included babesiosis as nationally notifiable diseases in 2011. Immunocompromised individuals like those suffering with HIV infection, cancer, hemoglobinopathy, organ transplantation are at high risk of contacting babesiosis and demonstrate more severe symptoms and persistent infection. Other factors that make one vulnerable to contacting babesiosis are age, drug regime of immunosuppressive drugs or recent splenectomy. The disease shows a seasonal trend coinciding with the seasonal activity of ticks. Like any other protozoan parasites, Babesia inhabits an oxygen rich environment inside 
blood cells of mammalian host and faces a challenge of shielding its system against oxidative stress which may wreak havoc by damaging its membrane lipids, nucleic acids, and proteins. To counteract Reactive Oxygen Species (ROS), Babesia employs anti-oxidant systems including Thioredoxinthioredoxin reductase (Trx/TrxR) and Glutathione-Glutathione Reductase (GSH/GR). Thioredoxin system comprises of Thioredoxin reductase (TrxR), various thioredoxins and Thioredoxin-dependent peroxidases (TPx).Thioredoxin reductase has been biochemically characterized in Babesia [7]. Thioredoxin reductase belongs to a family of dimeric flavoenzymes. Thioredoxin reductase is an essential enzyme required for counteracting the oxidative stress and hence, in survival of these parasites. It is considered an attractive drug target as it plays key role in many cellular processes and its inhibition can affect many vulnerable stages in apicomplexan parasites. Not much is known about the functional and structural aspects of thioredoxin reductase of Babesia. Comparative modeling or homology modeling is an alternate method that aid in deriving structural insight about protein in absence of experimentally derived structure. Homology modeling has been used successfully for providing structural information of key enzymes in various instances in important human pathogens in past [8-17]. The enzyme of Babesia has pronounced and significant differences with the human counterpart. Hence, we undertook the exercise of developing a 3-dimensional model of Thioredoxin reductase enzyme of Babesia microti for obtaining insights about its structure and function.

\section{Materials and Methods}

\section{Sequence retrieval and physicochemical characterization}

Uniprot database (http://www.uniprot.org/) was searched using keyword "Babesia microti" and thioredoxin reductase". The query yielded 7 entries. Primary sequence of the enzyme thioredoxin reductase of Babesia microti (Accession: A0A1R4AAX8) was collected in Fasta format from the database. Physicochemical properties of the enzymes were determined using Expasy-ProtParam and Protscale tool [18]. Charge and Pepstats of Emboss was used to determine position-wise distribution of charge mole percentage of various classes of amino acids in Thioredoxin reductase respectively.

\section{Propensity of crystallization}

CRYSTALP2 web server available at [19] and Xtalpred [20] were used to predict the propensity of enzyme to crystallize.

\section{Functional characterization of thioredoxin reductase of Babesia microti}

CYS REC server [21] that identifies the positions of cysteines, total number of cysteines and computes the most probable SS bond pattern of pairs in the protein sequence was used to analyse SS bonds in primary sequence.
Motifs were predicted using default parameters in MEME suite (Multiple Em for Motif elicitation) [22].

Consurf server was employed for identification of biologically important protein residues in the protein sequence $[23,24]$. As three-dimensional structure of the protein is not available in Protein Data Bank (PDB) (http://www.rcsb.org/pdb), this study aimed at development of 3D model of thioredoxin reductase of Babesia microti and conducting in-depth sequence and structural analysis.

\section{Secondary structure prediction from target sequence}

Secondary structure of a protein denotes the arrangement of residues in alpha helix, beta sheets, extended strands or turns. Secondary structure of the selected protein was predicted employing NPS server [25] using various methods viz. DPM [26], DSC [27], GOR4 [28], HNNC [29], PHD [30], Predator [31], SOPMA [32], SIMPA96 [33] and secondary consensus [34] keeping default parameters for 4 state predictions keeping output width=70.

\section{Prediction of protein disorder}

Often post translational modifications, attachment of signal peptides, evolutionary path of a protein molecule are dictated by the disordered regions present in a protein molecule. Thus, identification of such important disordered regions is of immense importance to understand the structure and function of a protein. Disordered regions of the thioredoxin reductase were identified using DisEMBL [35], GLOBPLOT [36], RONN [37] and Protein Disorder Prediction System (PRDOS) [38] server.

\section{Generation of three dimensional models}

Comparative modeling approach was adopted to derive a $3 \mathrm{D}$ model of thioredoxin reductase of Babesia microti. The spatial restraint based Modeller 9.19 version was used for this purpose. The complete modeling exercise included target based template searching and selection, target-template alignment, model development employing spatial restraint, model evaluation, loop optimization and final structural quality evaluation. For further assurance and better template consideration, we have also attempted parallel template selection through Swiss model [39].

\section{Selection of template}

For template selection, the first approach model generation method of Swiss model [39] was used. On the basis of obtained result, high-resolution X-ray crystallography structure of thioredoxin glutathione reductase at a resolution of $2.30 \AA$ (PDB ID: 2x99, A chain) [40] having 48.22\% identity with the query sequence was selected as template for homology modeling exercise. In parallel, template searches were performed through Modeller 9.19 version [41] via profile development and searching. Reasonable number of hits (20; 1 aogA, 1 jot, 3grs, 1trb, 1dxlA, 1ebdA, 1nhp, 1fecA, 1 gesA, 1h6vA, 1jehA, 3ladA, 1lpfA, 1lvl, 1mo9A, 1onfA, 1vdc, 
1xdiA, 1q1rA, 1xhcA) was obtained through this process and all the obtained templates were compared on the basis of their sequence length coverage (sequence identity) and crystal structure resolution.

\section{Target-template alignment}

Out of the selected total number of templates (20 from Modeller analysis and 2x99A from SwissModel), further reduction in number of templates was done following the sequence identity and structural resolution based criterion. The following templates were selected: 1mo9A, 1xhcA, 1nhpA, 1xdiA, 1lvlA, 1h6vA, 1q1rA. A template-template comparison was done to reach such conclusion. Target-template alignment was done using the Modeller based scripts (Modeller version 9.19). The template (2x99A) selected through the Swiss Model tool was also included in the final template list.

\section{Model development and evaluation}

The target sequence was carefully aligned with the generated multi-template alignment. Total 10 models were generated based upon the multi-template-target alignment. All the models were subjected to PDF, DOPE and GA341 evaluation. The best model was selected after carefully analyzing the obtained values, especially the DOPE scores. GA341 output suggested that the structures were similar to the original crystal structures in quality.

\section{Loop optimization and further structural evaluation}

The best model was selected and visually inspected using VMD [42] and Chimera [43]. The observation suggested that the model contained multiple sheets and helices along with several loops. Considering the generation of multiple loops, multi-template based approach was adopted so as to generate a structure with comparatively shorter loops. Loop optimization was mandatory considering the presence of multiple loops in the structure. Based on the visual inspection and other external systematic evaluation (RAMPAGE [44], ERRAT [45] etc.), regions with loops having comparatively poor energy were subjected to refinement. Total 10 structures with loop refinement were generated and further evaluated. Obtained results pertaining to the template selection through structure development and evaluation are described in the result section.

\section{Structure validation}

Followed by the structure validation through DOPE score, GA341 and modeler objective function, all the structures were further subjected to validation through RAMPAGE, PROSA (Protein Structure Analysis) and ANOLEA (Atomic Non-Local Environment Assessment). Analysis detail is provided in the result section.

\section{Secondary structural analysis from final protein structure}

To understand the three-dimensional structure with details of secondary, tertiary and quaternary features, further structural analysis with PDBSUM and PROMOTIF [46] was performed. Detailed insight on all the sheets, helices, loops, hairpins, disulphide linkages along with specific motifs and orientation was obtained for the generated structure.

\section{Active site prediction}

Identification of active site is important to understand the plausible pockets present in a protein which can be considered for safe binding sites for potential inhibitors which may aid in hindering the structural and functional mechanism of an important protein molecule belonging to a pathogen. With such objective, potential active site mapping was done using CASTp tool [47] to retrieve information regarding the microenvironment of the pockets of the target protein.

\section{Ligand selection and docking analysis}

Antibiotic resistance has become a cause of concern globally. The drug pipeline should be replenished from time to time with novel natural or synthetic molecules to provide remedy to the patients from various infections. Similar situation demands for novel active molecules for Babesia too. Recent report by Harbut et al. [48] suggested that Auranofin is having excellent potential to exhibit bactericidal role affecting the thiol-redox homeostasis. Interestingly, it was found in the same study that Auranofin can be used for other gram positive bacteria too such as Bacillus subtilis, Enterococcus faecalis, Enterococcus faecium and Staphylococcus aureus. Auranofin functions through creating oxidative stress for the bacteria through diminishing their reducing capacity. Thus, this potential molecule may become a common purpose inhibitor for several gram positive pathogens.

Following the vital information, similar compounds from the PubChem databases were utilized which showed maximum structural similarity with the auranofin molecule. Total 33 such molecules were selected including different conformations that were used for the docking purpose against the developed structure. Structures having 3D information were only considered. SwissDock server [49] was utilized for this purpose.

\section{Protein dynamics simulation for fluctuations}

Fluctuation of protein provides insight in relation to the stability and flexibility of a protein. Simulated molecular motion analysis provides ample information in this regard. Different types of molecular motion analysis were performed for the target protein to understand the flexibility and plausible direction of the motion in the target protein. CABSflex [50] was used for this purpose.

\section{Results and Discussion}

The goal of this computational analysis was to retrieve indepth molecular information with relation to the target protein considered for this study. Analyzing the protein in a comparative manner through integrated sequential, structural and functional analyses yielded novel insights for Babesia 
microti thioredoxin reductase protein. The following result section describes such information in detail.

\section{Sequence retrieval and physicochemical characterization}

Initial investigation of the protein sequence suggested some important information that is summarized in the Table 1. The length of the protein was found to be 553 amino acids having overall molecular weight of 60329.49. The higher molecular weight suggests that out of various types of thioredoxin reductase, this protein might have similarity with glutathione reductase, trypanothine reductase and such other enzymes [51].

The enzyme was predicted to be non-crystallizable with 0.463 confidence by CRYSTALP and least crystallizable both in EP crystallization (Class: 3) and RF crystallization classes (Class: 11). SPpred (Soluble Protein prediction) results showed a score indicating that thioredoxin reductase of Babesia microti is a soluble protein.

Theoretical pI of the protein was estimated to be 7.56, suggesting the point where the net charge of the protein could be nil. The theoretical pI value helps in different experimental set up pertaining to the protein for isolation and purification. The extinction coefficient value is another important parameter in relation to experimental calculations providing the absorption value of the protein. The obtained instability index value (Table 1) 31.12 represents the theoretical stability of the protein even after being a quite large molecule. Similarly, the aliphatic index value of 93.58 (Table 1) suggests the major relative volume occupancy of the aliphatic side chains for this Babesia thioredoxin reductase. Grand Average of Hydropathicity (GRAVY) value of -0.016 demonstrates the hydrophilic nature of the protein.

Table 1. Physicochemical properties of thioredoxin reductase of $B$. microti determined using protparam.

\begin{tabular}{|c|c|c|}
\hline S. no. & Property & Value \\
\hline 1. & Number of amino acids & 553 \\
\hline 2. & Molecular weight & 60329.49 \\
\hline 3. & Theoretical pl & 7.56 \\
\hline 4. & Total number of negatively charged residues & 56 \\
\hline 5. & Total number of positively charged residues & 57 \\
\hline \multirow[t]{2}{*}{6.} & Formula & $\mathrm{C}_{2687} \mathrm{H}_{4276} \mathrm{~N}_{722} \mathrm{O}_{798} \mathrm{~S}_{2}$ \\
\hline & & 7 \\
\hline 7. & Total number of atoms & 8510 \\
\hline 8. & Ext. coefficient & 43945 \\
\hline 9. & Ext. coefficient ${ }^{\star}$ & 43320 \\
\hline 10. & Instability index & 31.12 \\
\hline 11. & Aliphatic index & 93.58 \\
\hline 12. & Grand average of hydropathicity (GRAVY) & -0.016 \\
\hline
\end{tabular}

\begin{tabular}{lll}
\hline 13. & $\begin{array}{l}\text { Estimated half-life (mammalian reticulocytes, } \\
\text { in vitro) }\end{array}$ & $>30$ \\
\hline 14. & Estimated half-life (yeast, in vivo) & $>20$ \\
\hline 15. & Estimated half-life (Escherichia coli, in vivo) & $>10$ \\
\hline
\end{tabular}

\section{Amino acid composition}

Prediction results showed that leucine (Table 2) was the most abundant amino acid followed by glycine and valine. Secondary structure of a protein is representation of repetitive geometrical conformations formed as a result of intermolecular and intramolecular hydrogen bonding. Most of the servers predicted that random coils were predominant structures in the protein followed by alpha helices and extended strands.

Eleven cysteines at position 17, 105, 110, 200, 251, 278, 306, 419, 471, 547 and 552 were predicted using CYSRec. Out of these, 7 are not S-S bounded, 1 is probably S-S bounded. Only 2 cysteines (536) showed high score and are probably S-S bounded. Most probable pattern is 105-110.

Table 2. Amino acid composition of thioredoxin reductase of $B$. microti predicted using protscale.

\begin{tabular}{|c|c|c|c|}
\hline S. no. & Amino acid & Number & Percentage \\
\hline 1 & Ala & 37 & $6.70 \%$ \\
\hline 2 & Arg & 21 & $3.80 \%$ \\
\hline 3 & Asn & 29 & $5.20 \%$ \\
\hline 4 & Asp & 34 & $6.10 \%$ \\
\hline 5 & Cys & 11 & $2.00 \%$ \\
\hline 6 & Gln & 12 & $2.20 \%$ \\
\hline 7 & Glu & 22 & $4.00 \%$ \\
\hline 8 & Gly & 48 & $8.70 \%$ \\
\hline 9 & His & 13 & $2.40 \%$ \\
\hline 10 & Ile & 38 & $6.90 \%$ \\
\hline 11 & Leu & 51 & $9.20 \%$ \\
\hline 12 & Lys & 36 & $6.50 \%$ \\
\hline 13 & Met & 16 & $2.90 \%$ \\
\hline 14 & Phe & 22 & $4.00 \%$ \\
\hline 15 & Pro & 23 & $4.20 \%$ \\
\hline 16 & Ser & 39 & $7.10 \%$ \\
\hline 17 & Thr & 34 & $6.10 \%$ \\
\hline 18 & Trp & 3 & $0.50 \%$ \\
\hline 19 & Tyr & 18 & $3.30 \%$ \\
\hline 20 & Val & 46 & $8.30 \%$ \\
\hline
\end{tabular}

Proportion of different classes of amino acids in thioredoxin reductase of $B$. microti is represented in Table 3 suggesting dominance of non-polar amino acids followed by small and 
polar amino acids. Periodicity of polar and non-polar amino acids along with the existence of disordered regions determines the secondary structure of a protein molecule, especially its tendency of developing $\alpha$-helices and $\beta$-sheets [52].

Table 3. Mole percentage of different classes of amino acids present in thioredoxin reductase of B. microti using emboss.

\begin{tabular}{lllll}
\hline S. no. & Property & Residues & Number & Mole (\%) \\
\hline 1 & Tiny & $(\mathrm{A}+\mathrm{C}+\mathrm{G}+\mathrm{S}+\mathrm{T})$ & 169 & 30.561 \\
\hline 2 & Small & $(\mathrm{A}+\mathrm{B}+\mathrm{C}+\mathrm{D}+\mathrm{G}+\mathrm{N}+\mathrm{P}+\mathrm{S}+\mathrm{T}+\mathrm{V})$ & 301 & 54.43 \\
\hline 3 & Aliphatic & $(\mathrm{A}+\mathrm{l}+\mathrm{L}+\mathrm{V})$ & 172 & 31.103 \\
\hline 4 & Aromatic & $(\mathrm{F}+\mathrm{H}+\mathrm{W}+\mathrm{Y})$ & 56 & 10.127 \\
\hline 5 & Non-polar & $(\mathrm{A}+\mathrm{C}+\mathrm{F}+\mathrm{G}+\mathrm{l}+\mathrm{L}+\mathrm{M}+\mathrm{P}+\mathrm{V}+\mathrm{W}+\mathrm{Y})$ & 313 & 56.6 \\
\hline 6 & Polar & $(\mathrm{D}+\mathrm{E}+\mathrm{H}+\mathrm{K}+\mathrm{N}+\mathrm{Q}+\mathrm{R}+\mathrm{S}+\mathrm{T}+\mathrm{Z})$ & 240 & 43.4 \\
\hline 7 & Charged & $(\mathrm{B}+\mathrm{D}+\mathrm{E}+\mathrm{H}+\mathrm{K}+\mathrm{R}+\mathrm{Z})$ & 126 & 22.785 \\
\hline 8 & Basic & $(\mathrm{H}+\mathrm{K}+\mathrm{R})$ & 70 & 12.658 \\
\hline 9 & Acidic & $(\mathrm{B}+\mathrm{D}+\mathrm{E}+\mathrm{Z})$ & 56 & 10.127 \\
\hline
\end{tabular}

Improbability of expression in inclusion bodies for the considered protein was found to be 0.792 suggesting the probable tendency of the protein with reference to its presence in the inclusion bodies and thus hinting the possible way of purifying the same without losing the enzymatic activity. The other important physicochemical properties along with their respective value ranges are provided in Table 4.

Table 4. Minimum and maximum values of physicochemical properties of thioredoxin reductase of $B$. microti predicted using protscale.

\begin{tabular}{|c|c|c|c|}
\hline s. no. & Property & Minimum value & Maximum value \\
\hline 1. & Bulkiness & 0.197 & 0.828 \\
\hline 2. & Polarity & 0.001 & 0.556 \\
\hline 3. & Refractivity & 0.108 & 0.515 \\
\hline 4. & Recognition factor & 0.065 & 0.632 \\
\hline 5. & $\begin{array}{l}\text { Hydrophobicity } \\
\text { Doolittle) }\end{array}$ & 0.246 & 0.819 \\
\hline 6. & Transmembrane tendency & 0.329 & 0.839 \\
\hline 7. & Buried Residues & 0.218 & 0.846 \\
\hline 8. & Accessible residues & 0.323 & 0.701 \\
\hline 9. & Ratio hetero end/side & 0.030 & 0.442 \\
\hline 10. & Average area buried & 0.115 & 0.542 \\
\hline 11. & Average flexibility & 0.329 & 0.852 \\
\hline 12. & Relative mutability & 0.218 & 0.767 \\
\hline
\end{tabular}


structure, mechanism of action, variation in coding genes, therefore, each thioredoxin structure should be analysed with individual attention.

Table 7. Disordered regions by definition using different servers.

\begin{tabular}{llll}
\hline S. no & Server & Definition by type & Region \\
\hline 1 & Pondr & Disordered regions & $172-177,187-188,213-218,336-357,367-367,377-382$ \\
\hline 2 & DisEMBL & Disordered by loops/coils definition & $\begin{array}{l}4-71,62-70,86-112,133-144,180-195,208-240,289-322,327-380,394-423, \\
456-481,488-495,509-553\end{array}$ \\
\cline { 3 - 4 } & & Disordered by hot-loops definition & $93-103,134-145,167-196,208-217,460-469,536-553$ \\
\cline { 3 - 4 } & GLOBPLOT & Disordered by Remark-465 definition & $538-553$ \\
\hline 3 & Disordered by Russell/Linding definition & $61-71,92-106,210-219,230-237,463-468,536-553$ \\
\cline { 3 - 4 } & & Potential globular domains (GlobDoms) by & 1-91, 107-551 \\
& Russell/Linding definition & \\
\hline
\end{tabular}

\section{Transmembrane region prediction}

As the transmembrane helix regions scoring above 500 only are considered significant, only 2 regions (2-21, 239-266, inside to outside helices) and 1 (96-114, Outside to inside helices) predicted were considered (Figure 1).

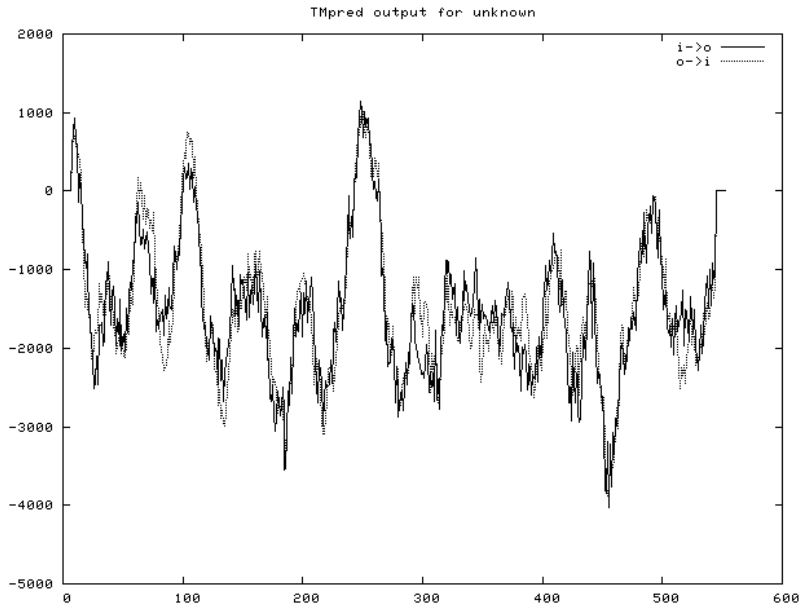

Figure 1. Transmembrane region prediction using TMPRED.

\section{Disordered regions in the target protein}

Identification of disordered regions in a protein molecule is of vital importance to understand the structural, functional and evolutionary aspect of a protein. It is imperative to understand the disordered regions of this protein considering its structural and functional diversity. The predicted disordered regions are provided in Table 7 and Figure 2.

\section{Sequence-structure conservation analysis}

Consurf server $[23,24]$ was used for finding the evolutionary significance of amino acids in thioredoxin reductase protein sequence of $B$. microti with the default options of BLAST Evalue threshold: 0.001 , maximum number of homologs: 50 , iteration $=1$. Multiple sequence alignment was built using MAFT and UNIREF90 was used for collection of homologues using HMMER homology search algorithm. Out of 1366 HMMER hits, 1242 were found to be unique and the calculation was performed on the 50 sequences closest to the query. The conservation scores versus residue number and the unrooted phylogenetic tree constructed using the tree building facility of CLUSTAL-W employing the multiple sequence alignment obtained from MUSCLE are shown in Figure 3.

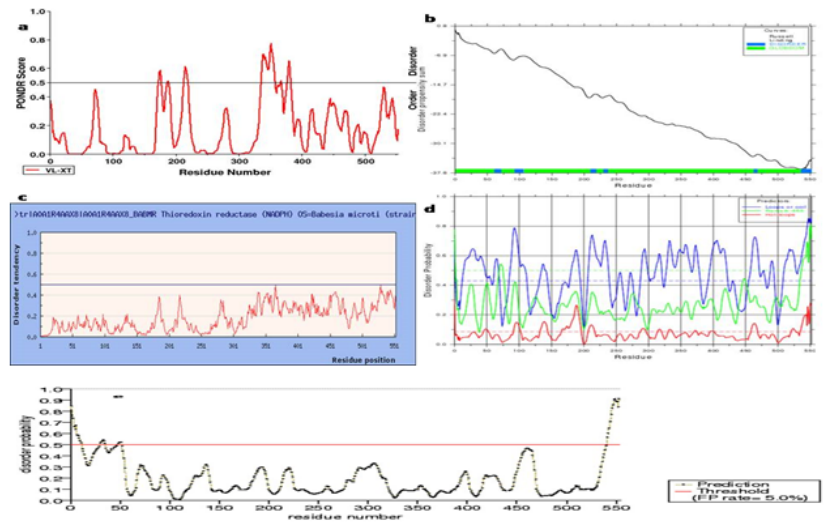

Figure 2. Protein disorder of thioredoxin reductase of Babesia microti predicted using (a) PONDR, (b) GLOBPLOT (c) IUPRED (d) DisEMBL and (e) PRDOS

\section{Structure generation through homology modeling}

As mentioned in the methodology section, homology modeling for the target sequence was attempted using Modeller 9.19 version. Following the protocol discussed, profile was built and relevant structures were searched through Modbase. Rigorous experiment was conducted to develop a model from a single template where PDB ID 2x99 chain "A" (best template found through SwissModel server) and $1 \mathrm{mo} 9$ chain "A" (best template found in Modbase template search) were used as templates. But due to template-target length difference, single template based approach was not adequate to provide expected result. Therefore, a multi-template based approach was adopted. Figure 4A shows the potential important templates obtained during template search along with their respective 
sequence identity, structural resolution and sequence coverage. Altogether, twenty one (21) templates were obtained and the best identity and templates with good structural resolution containing (1mo9A, 1xhcA, 1nhpA, 1xdiA, 1lvlA, 1h6vA, 1q1rA and $2 \times 99 A$ ) were considered for multi-template based modeling (Figure 4B). Generated target-template alignment is shown in Figure 5.
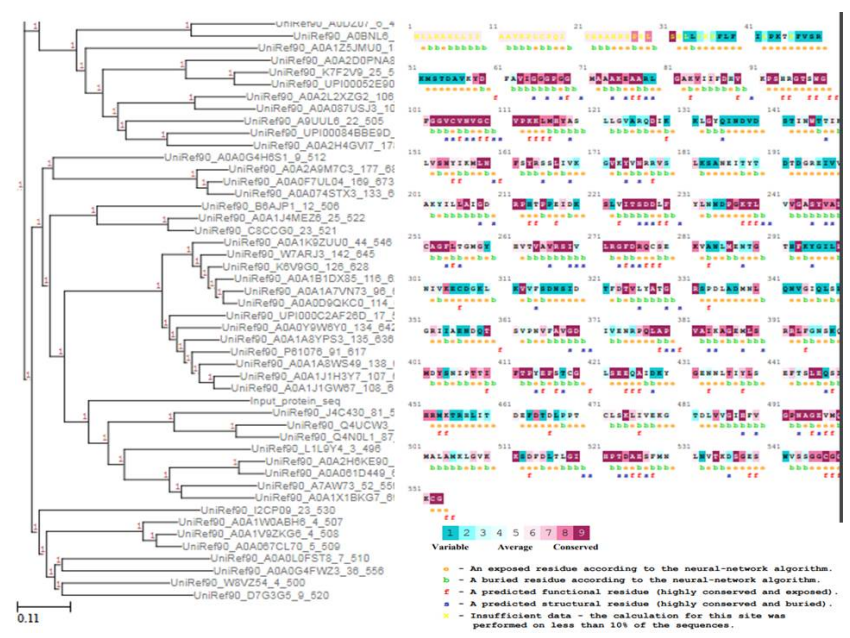

Figure 3. Consurf results showing conserved amino acid with scores.

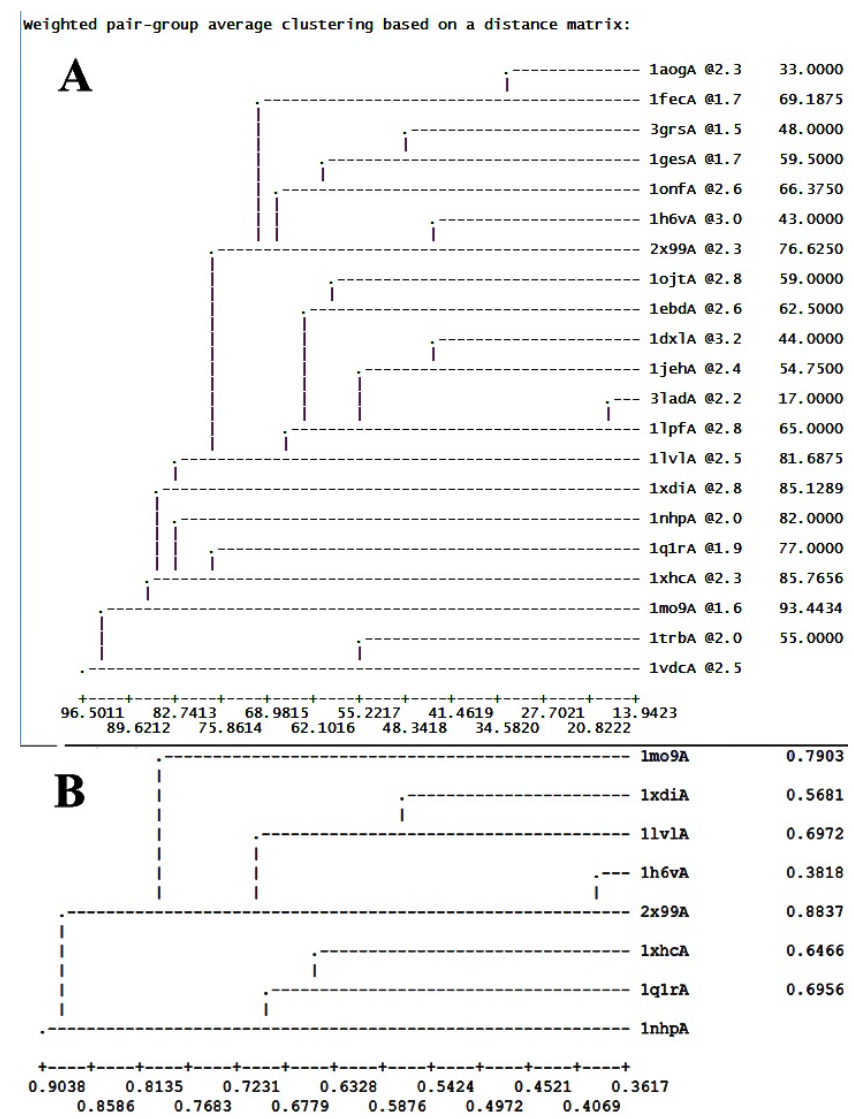

Figure 4. Template selection for three dimensional structural development through modeller. (A) The obtained initial hits as templates. (B) Comparative identity of the selected templates for multi-template based modelling.

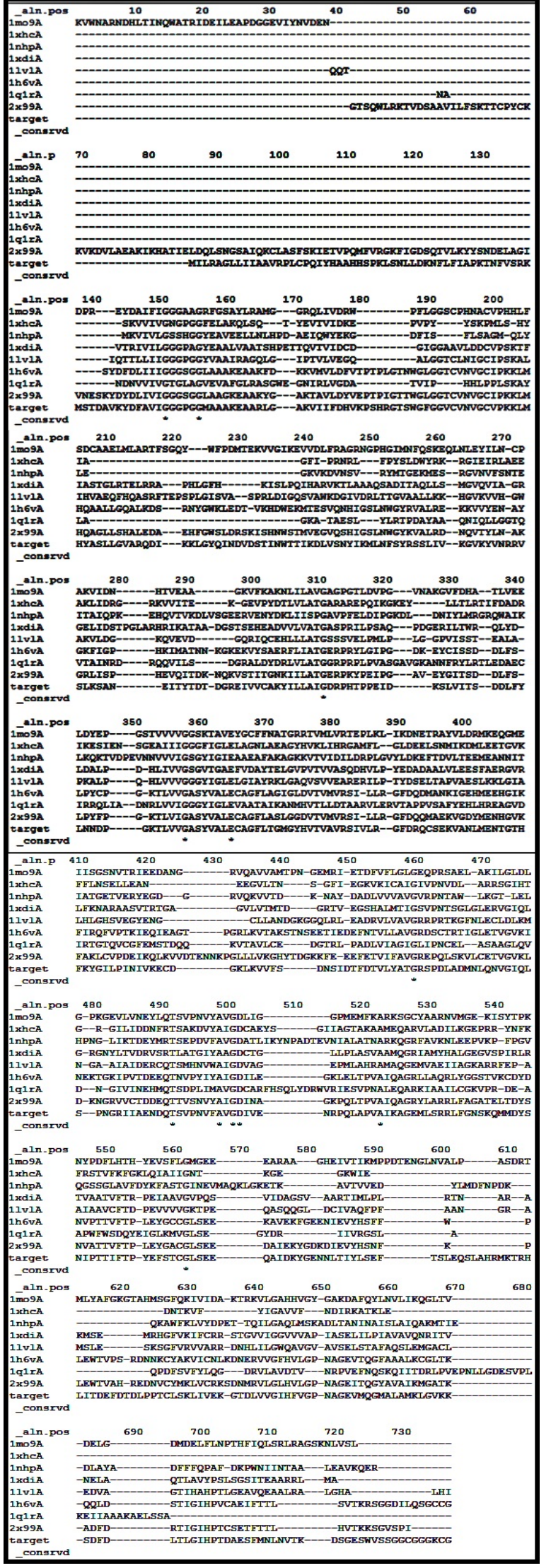

Figure 5. Generated target sequence and multiple template alignment. 
Once the target-template alignment was generated, ten protein structures were developed for the target protein using the multi-template and target sequence alignment. All the proteins were further subjected to evaluation through molpdf, DOPE and GA341 scoring. The obtained results are displayed in Table 8 along with their respective model numbers. The $4^{\text {th }}$ model was found to be comparatively good based on the above mentioned evaluation scoring and was considered for the further analysis. The obtained model is represented in new cartoon format and surface view in Figure 6. The developed structure showed the alpha helices and beta sheets almost similar to other thioredoxin reductase proteins along with some long loops.

Table 8. Molpdf, DOPE score and GA341 score of best ten three dimensional structural models developed with multiple templates.

\begin{tabular}{llll}
\hline Model number & molpdf & DOPE & GA341 \\
\hline Model 4 & 27163.44336 & -55457.5 & 1 \\
\hline Model 1 & 26907.65625 & -55397.7 & 1 \\
\hline Model 10 & 26742.1875 & -55374.7 & 1 \\
\hline Model 7 & 26880.80469 & -55139.8 & 1 \\
\hline Model 8 & 26782.80469 & -54850.4 & 1 \\
\hline Model 6 & 27027.62305 & -54804.3 & 1 \\
\hline Model 5 & 27123.99609 & -54774.9 & 1 \\
\hline Model 2 & 27446.76563 & -54381.3 & 1 \\
\hline Model 3 & 27149.9707 & -54333.4 & 1 \\
\hline Model 9 & 27038.10547 & -54202.5 & 1 \\
\hline
\end{tabular}

\section{Loop optimization of the best structure}

The existence of multiple loops suggested the further need for loop optimization. Therefore, all loop regions with poor energy profile and structural orientation were identified using energy profiling and structural evaluation and visualization and the structure was subjected to loop optimization.

Table 9. molpdf and DOPE score of best ten loops optimized three dimensional structural models developed with multiple templates.

\begin{tabular}{lll}
\hline Structure model number & molpdf & DOPE \\
\hline Model 8 & 1184.14331 & -10252.12012 \\
\hline Model 2 & 1651.75635 & -9835.49707 \\
\hline Model 1 & 903.81464 & -9727.25488 \\
\hline Model 4 & 2020.79944 & -9114.76074 \\
\hline Model 9 & 5959.34863 & -8566.29785 \\
\hline Model 6 & 3826.18115 & -8330.34473 \\
\hline Model 5 & 4257.93311 & -8059.69629 \\
\hline Model 3 & 5646.4541 & -8047.19873 \\
\hline Model 7 & 4218.79346 & -7961.8457 \\
\hline
\end{tabular}

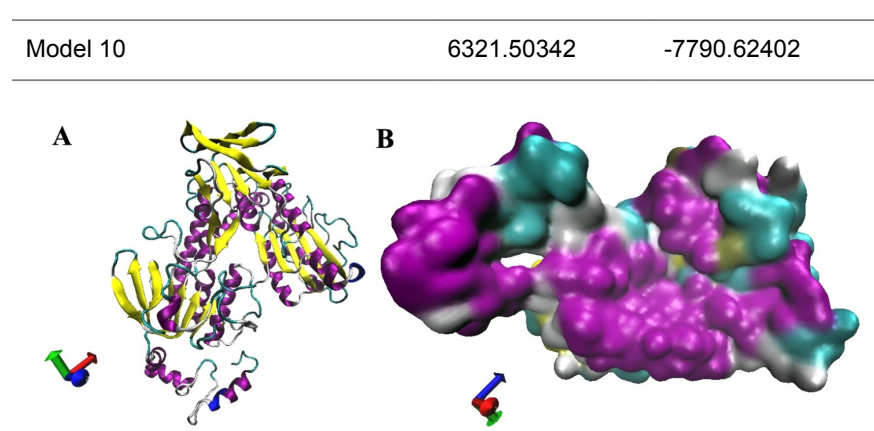

Figure 6. Three dimensional structure of thioredoxin reductase of $B$. microti visualized using VMD. (A) Representation of the $\alpha$ helices (purple), $\beta$ sheets (yellow) and loops (cyan) of the final protein generated after loop optimization through multiple-template based modeling approach. (B) Surface view of the protein where purple colored surface refers to the $\alpha$-helix region and cyan loops.

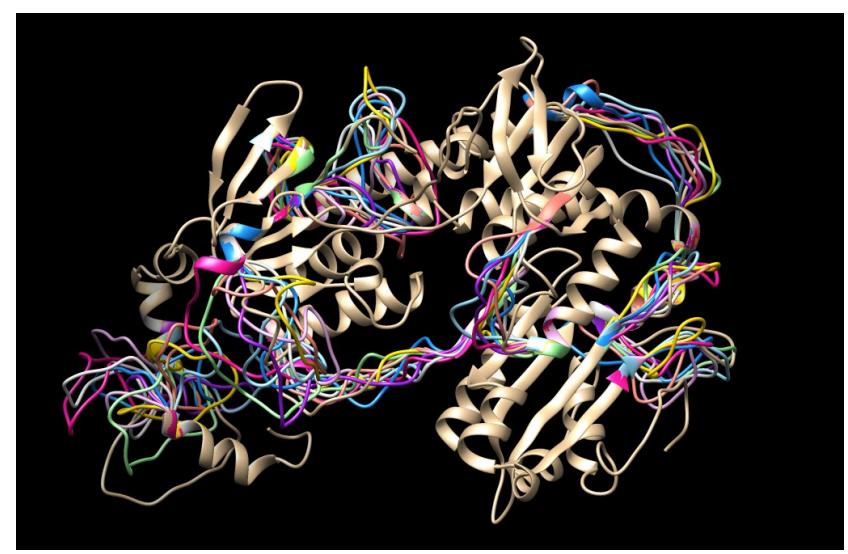

Figure 7. Three dimensional structure of thioredoxin reductase of $B$. microti with the loops optimized for 10 structures visualized using chimera.

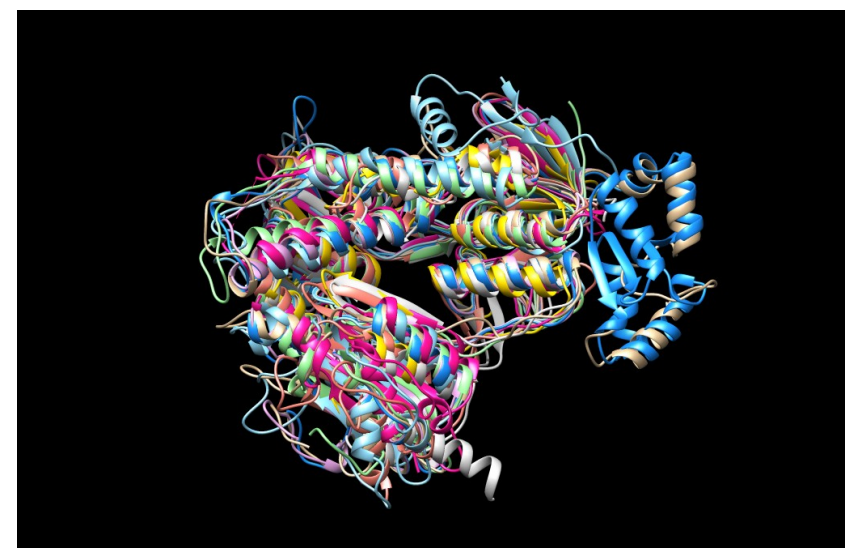

Figure 8. Superimposed target-template structures. The target is represented in light grey and all other templates are depicted in various other colors superimposed with the target protein molecule.

The evaluation scores for the 10 models developed during loop optimization considering the previous multi-template based best structure as starting structure are provided in Table 9. The model 8 was found to be the best loop optimized model and was considered for all relevant analysis. Figure 7 represents the structures with loops after optimization. 


\section{Structure validation}

The final structure was identified after the loop modeling and subjected to superimposition with the considered multiple templates. The obtained RMSD was within the allowed region for most of the templates. The superimposition of the final modeled structure with multiple templates is shown in Figure 8. Respective RMSD value ranges and distance observed between the target and the templates are represented in Figure 9. The RMSD values ranged from $0.506 \AA$ to $2.457 \AA$.
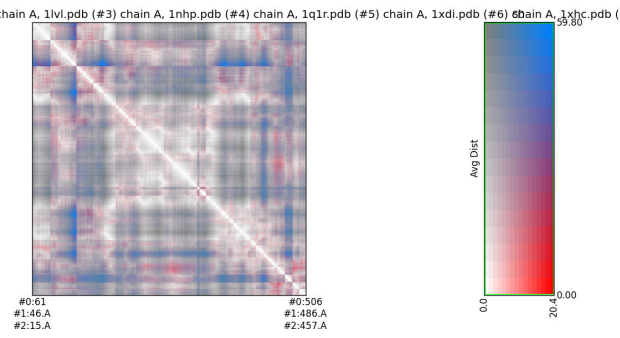

Figure 9. Target-templates superimposition distance matrix with distance values and standard deviations. This is a $2 D$ matrix representation of the target and the template proteins where ranges of deviations are represented in angstrom.

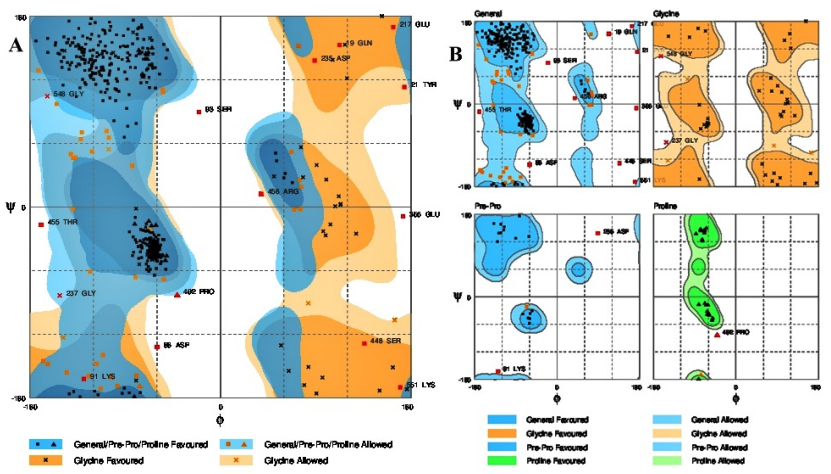

Figure 10. Stereochemical quality check using RAMPAGE.

The final structure was further evaluated for stereo-chemical structural quality through various standard tools such as RAMPAGE [44], PROSA [53] and ANOLEA.

\section{RAMPAGE analysis}

Stereochemical quality of model was checked using RAMPAGE server (Figure 10). Ramachandran plot obtained using RAMPAGE revealed that $90.2 \%$ of residues were within the most favored regions. Residues falling in additionally allowed regions and outlier residues in outlier region were 7.1 $\%$ and $2.7 \%$ respectively.

\section{Validation through PROSA}

PROSA (Protein Structure Analysis) was used to evaluate the quality of $3 \mathrm{D}$ models of protein structures. Z-score is a measure of overall model quality and denotes the deviation of the total energy of the structure compared to energy distribution derived from random conformations. The PROSA score was -7.71 for the modeled protein, which indicates its correctness.
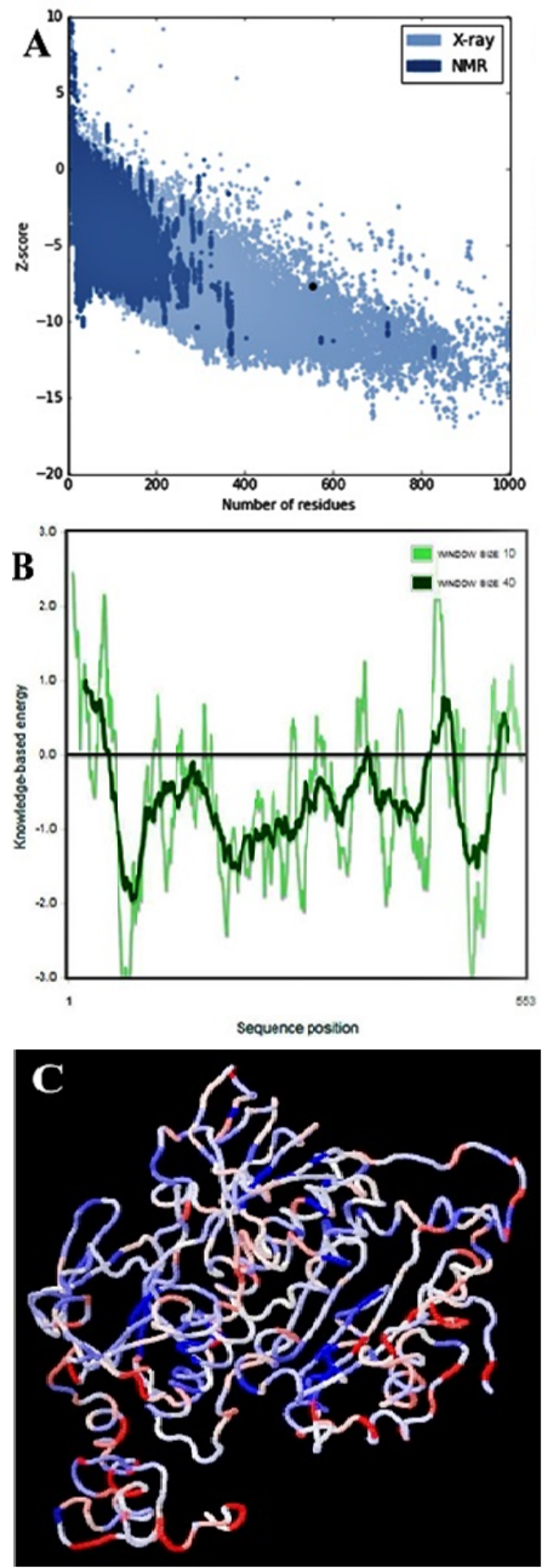

Figure 11. PROSA analysis of the modeled structure for structural evaluation (A) The black dot shows the position of the modeled structure with comparison to the existing X-ray crystallography generated and NMR based structures. (B) Comparative estimation of the energy profile with relation to the knowledge-based energy profiles. (C) Depiction of the structure based on the energy values where "blue" represents lowest energy and "red" represents highest energy in the protein. 
PROSA profile for the target protein model was found better than all other template structures (PDB ID: 1mo9, chain "A"-11.77; PDB ID: 2x99, chain "A"-11.87; PDB ID: 1xhc, chain "A"-9.98; PDB ID: 1nhp, chain "A"-12.77; PDB ID: 1xdi, chain "A"-11.07; PDB ID: 1lvl, chain "A"-11.0; PDB ID: 1h6v, chain "A"-10.93 and PDB ID: 1q1r chain "A"-11.43). Zscore computed by PROSA for thioredoxin reductase of $B$. microti was found to be better than the Z-score of all the templates (Figure 11A). Negative values in PROSA plot with comparison to the knowledge based energy values indicated the stable regions of the protein and authentic model development (Figure 11B).

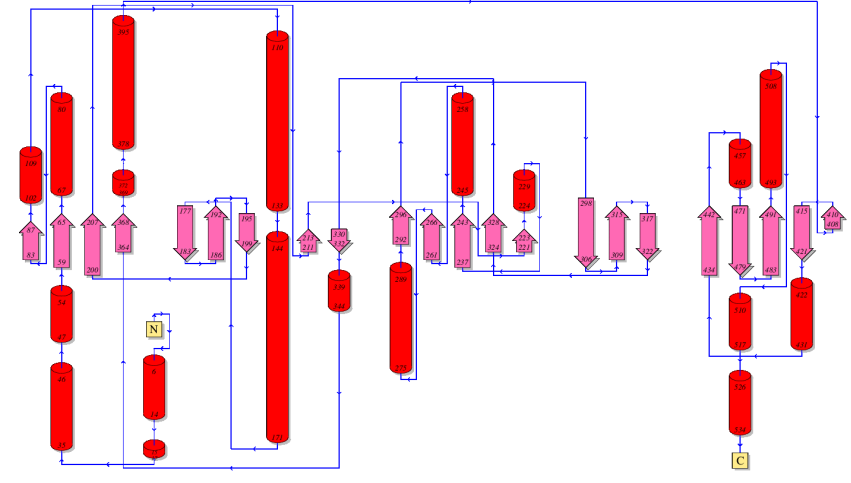

Figure 12. Complex protein topology displaying the direction of multiple helices and parallel and anti-parallel beta sheets generated for the target protein.

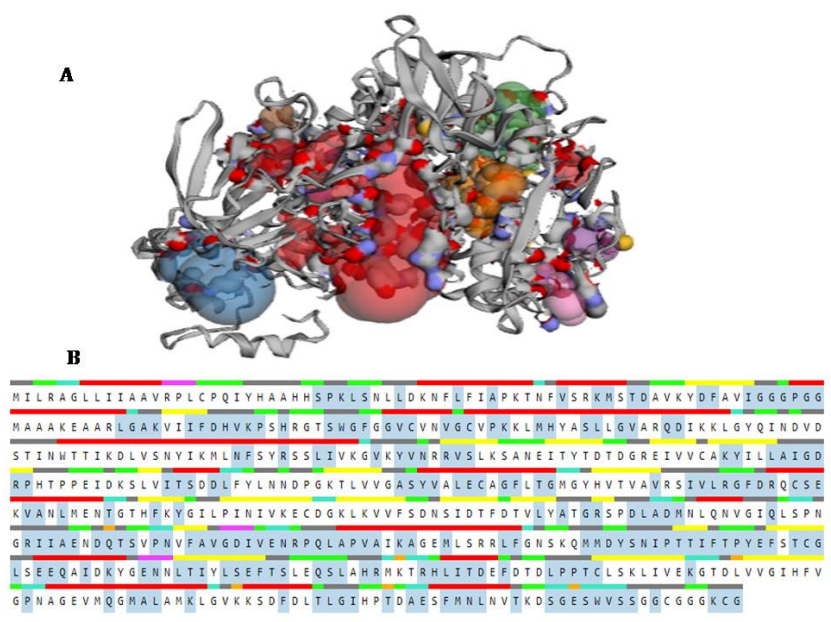

Figure 13. Depiction of top 10 pockets in target protein molecule.

\section{Analysis by ANOLEA}

Analysis of the modeled protein structure with ANOLEA (Atomic Non-Local Environment Assessment) [53] also provided expected outcome. The analysis was conducted with a window size of 9 amino acids. The results suggested that out of 553 amino acids, only 114 (20.61\%) showed comparatively higher energy. The Figure $11 \mathrm{C}$ also provided the similar information with a structural view. Computed non-local normalized energy Z-score of 2.80 was considerable for this large protein. The amino acids with high energy values were residue number 42; 52-56; 99-101; 132-135; 137-139; 151;
$212 ; 228-233 ; 256 ; 310-318 ; 332-337 ; 351-354 ; 440-460$; 494-498; 500-501; 507-539; 541-549.

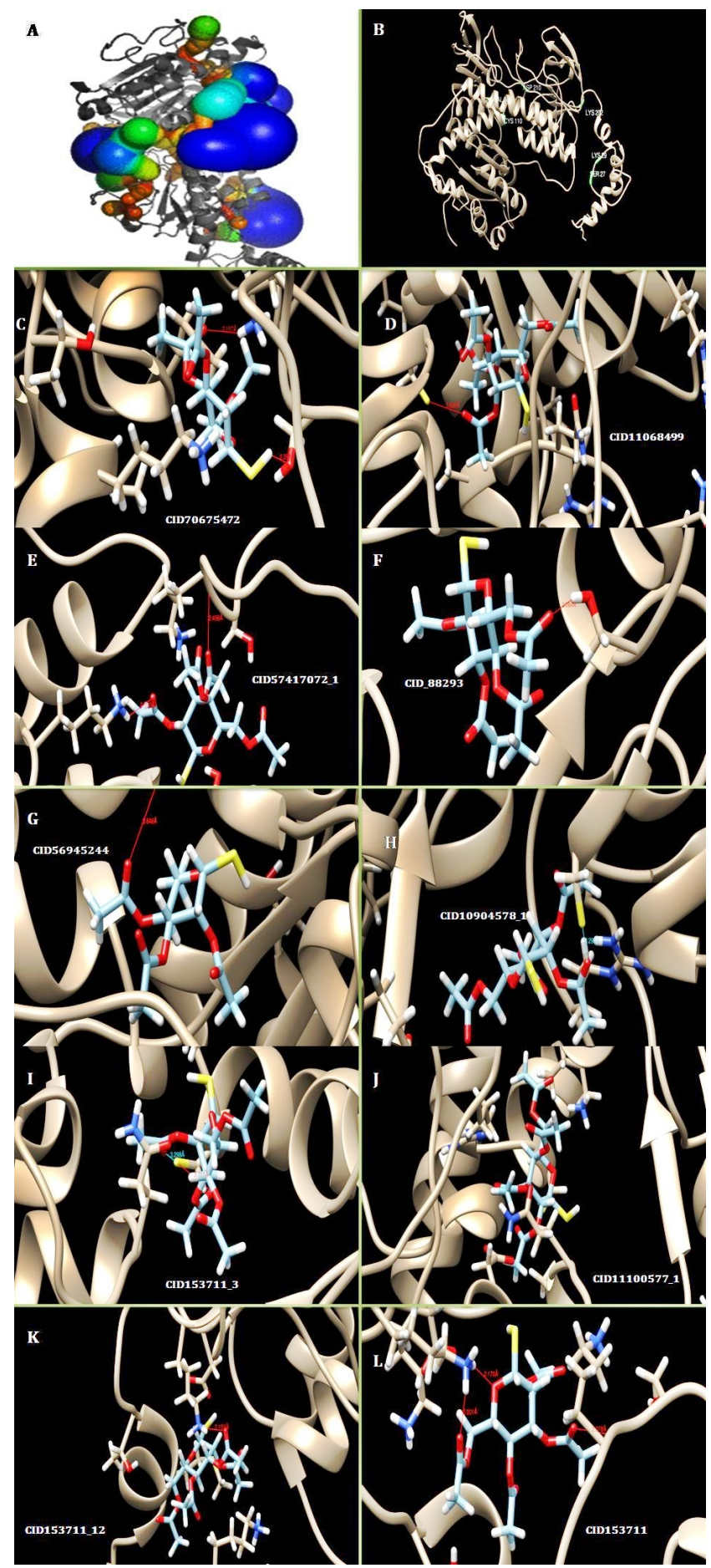

Figure 14. (A): Representation of the identified pores; (B): major residues participating in the interaction with ligand molecules and $(C-L)$ : docking modes of the top 10 molecules along with respective hydrogen bond interactions. Information related to detailed interactions is provided in Table 19.

\section{Structural topological analysis}

Structural topological analysis is important for this protein considering its complex structural and functional diversity. The 
outcome of the PROMOTIF topological analysis is provided in Figure 12.
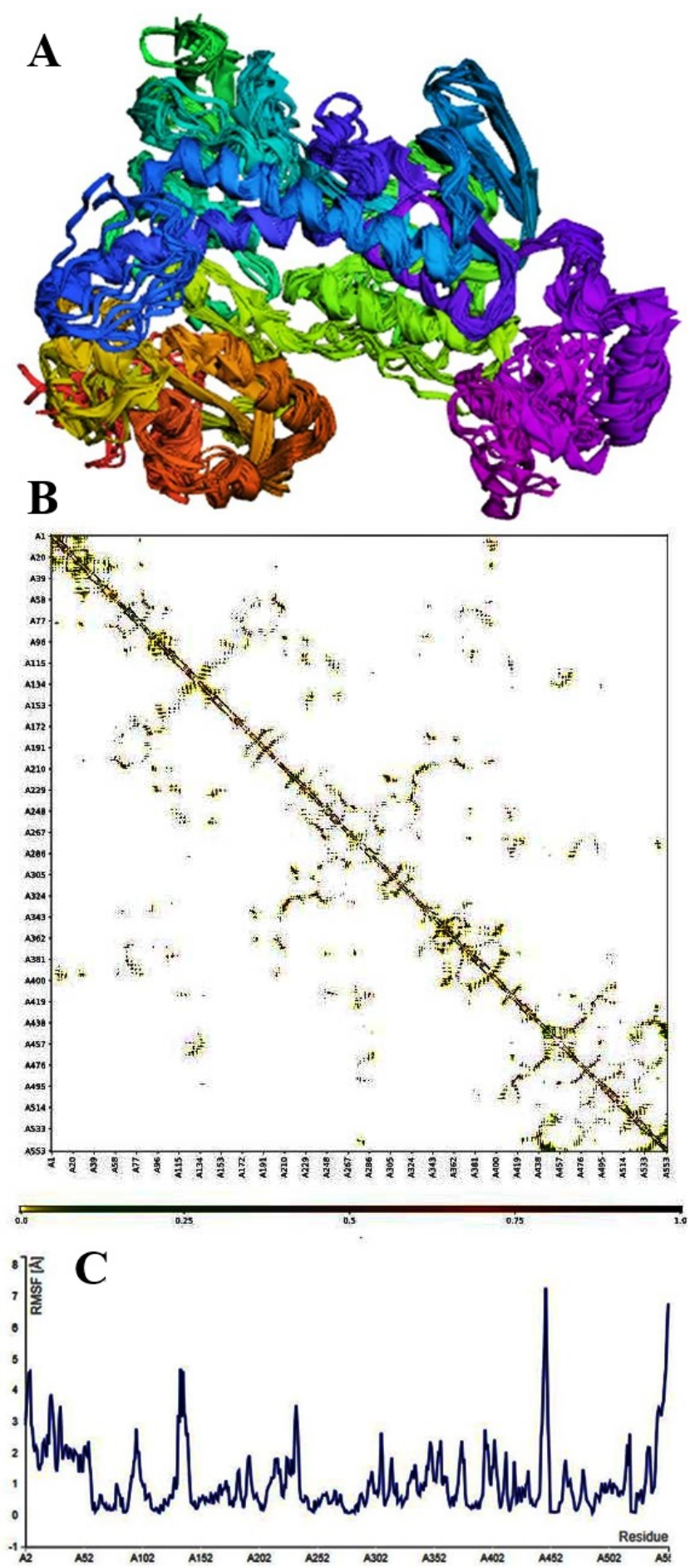

Figure 15. Flexibility analysis of the target protein. (A) Cartoon representation of top 10 models with fluctuations depicted in different color code. (B) Contact map generated for all 10 proteins. (C) Representation of obtained residue wise RMSF values for the structural models depicting the fluctuation for each residue in the protein structure.
The figure depicts the alpha helices, parallel and anti-parallel beta sheets and loop regions in detail along with the residue numbers. It is evident that the overall structure contains $22 \beta$ sheet regions, 19 helices and several loop regions.

\section{Secondary structural analysis from structure}

Detail secondary structural analysis was performed for the final protein structure developed. The post loop optimized best structure was utilized for this purpose and PROMOTIF was considered for the analysis.

As expected, the alpha helix portion was found to be maximum in the structure with 179 amino acids out of 553 being part of it which was $32.4 \%$ followed by the strand portion (108 amino acids (19.5\%)). 3-10 helix structures were found to be comprising of 5 amino acids $(0.9 \%)$ and other important structural component were constituted by 261 (47.2\%) amino acids. The overall structure contains several structural components such as beta sheets, beta-alpha-beta structural unit, beta-hairpins, beta-bulges, strands, helices, helix-helix interactions, beta turns, gamma turns and disulphide linkage. The detail description is provided in the following section.

Beta sheets: Total 6 beta sheets were found in the Babesia thioredoxin reductase structure. The number of strands varied from 2 to 5 as shown in Table 10. No barrel like structures were found for these predicted sheets. Presence of parallel and anti-parallel sheets were observed for this structure as represented with their respective topology in Table 10.

Table 10. Beta sheets present in the modeled structure along with number of strands, type and topology.

\begin{tabular}{lllll}
\hline Sheet & No. of strands & Type & Barrel & Topology \\
\hline A & 4 & Parallel & No & -1 X 2X 1X \\
\hline B & 3 & Antiparallel & No & 11 \\
\hline C & 2 & Antiparallel & No & 1 \\
\hline D & 5 & Parallel & No & -2 X - 1 X - 1X 3X \\
\hline E & 3 & Antiparallel & No & 11 \\
\hline F & 5 & Antiparallel & No & $-1-311$ \\
\hline
\end{tabular}

Beta-alpha-beta units: Beta-alpha-beta units are important structural components of thioredoxin reductase structure. Table 11 represents the strands along with the start, end residues and residues distributed in the helix and loop regions. This topology suggests the presence of alpha helical region sandwiched by beta sheets and most of the time such structural arrangement serves as a conserved topology in a protein structure.

Table 11. Distribution of the amino acid residues in the beta-alpha-beta units. 


\begin{tabular}{|c|c|c|c|c|c|c|c|c|}
\hline Strand 1 & & & Strand 2 & & & No. of helices & No. of residues & \\
\hline Start & End & Length & Start & End & Length & $\begin{array}{l}\text { No. of residues } \\
\text { in loop }\end{array}$ & $\begin{array}{l}\text { No. of residues in } \\
\text { helices }\end{array}$ & \\
\hline Tyr 59 & Ile 64 & 6 & Val 84 & Phe 87 & 4 & 1 & 19 & 14 \\
\hline Lys 238 & Val 242 & 5 & His 261 & Val 266 & 6 & 1 & 18 & 14 \\
\hline His 261 & Val 266 & 6 & His 292 & Tyr 295 & 4 & 1 & 25 & 15 \\
\hline
\end{tabular}

\section{Beta-hairpins units}

The beta-hairpin structural components suggest the presence of the anti-parallel beta sheets separated by a short loop region. Obtained structural regions are listed in Table 12 along with their respective hairpin class. Many hairpin classes were observed as provided in Table 12. Beta hairpin structural elements often indicate the folding pattern of a protein molecule and aid in unraveling the protein folding.

Table 12. Beta-hairpin regions in the modeled structure along with their classes.

\begin{tabular}{|c|c|c|c|c|c|c|}
\hline Strand 1 & & & Strand 2 & & & Hairpin \\
\hline Start & End & Length & Start & End & Length & \\
\hline Arg178 & Lys182 & 5 & Ile187 & Asp191 & 5 & $2: 4$ \\
\hline Ile187 & Asp191 & 5 & Glu196 & Val199 & 4 & $3: 5$ IG \\
\hline Pro299 & Cys306 & 8 & Lys309 & Phe314 & 6 & $2: 2$ II \\
\hline Lys309 & Phe314 & 6 & Ser318 & Phe322 & 5 & $2: 4$ \\
\hline Thr408 & lle410 & 3 & Phe416 & Gly420 & 5 & $5: 5$ \\
\hline Leu435 & Phe442 & 8 & Cys471 & Glu478 & 8 & $28: 28$ \\
\hline Cys471 & Glu478 & 8 & Val484 & Val490 & 7 & $4: 6$ \\
\hline
\end{tabular}

Beta-bulges: Beta bulges are important structural regions which are responsible for slight structural deviation in the beta sheets through introducing additional H-bonds in a beta sheet. They are categorized based on the length of disruption in the beta strand. Apart from simple distortion in the native structures, a beta bulge may have far reaching functional impact as well. Often, beta bulged regions may indicate an important structural region which may have been mutated yet maintained structural conservation considering the importance of the structural conservation in that particular region. The obtained beta bulges along with their respective types and impacted residue as res $\mathrm{X}$ are presented in Table 13.

Table 13. Beta-bulges in the modeled structure along with classes.

\begin{tabular}{llll}
\hline Bulge type & Res X & Res 1 & Res 2 \\
\hline Parallel bent & & Lys202 & Asp60 \\
\hline Antiparallel classic & His213 & Thr329 & Gly330 \\
\hline Antiparallel G1 & Cys306 & Gly308 & Lys309 \\
\hline
\end{tabular}

\begin{tabular}{llll}
\hline Antiparallel classic & Lys309 & Glu305 & Cys306 \\
\hline Antiparallel wide & Lys311 & Asp320 & Thr321 \\
\hline Antiparallel classic & Val313 & Ile300 & Asn301 \\
\hline Antiparallel classic & lle476 & Val485 & Gly486 \\
\hline Antiparallel G1 & Glu478 & Asp482 & Leu483 \\
\hline
\end{tabular}

Strands: The combination of helices and strands in thioredoxin reductase structure makes it unique and complex for its important function. The strand regions are presented in Table 14 along with their respective length.

Helices: Apart from strand regions, multiple helix regions also develop the backbone of the large thioredoxin protein. Obtained helices are presented in Table 15 along with their respective length.

Table 14. Components of the strand for the generated protein model.

\begin{tabular}{|c|c|c|c|}
\hline Start & End & Sheet & No.of residues \\
\hline Tyr59 & Ile64 & A & 6 \\
\hline Val84 & Phe87 & A & 4 \\
\hline $\operatorname{Arg} 178$ & Lys182 & $B$ & 5 \\
\hline Ile187 & Asp191 & B & 5 \\
\hline Glu196 & Val199 & B & 4 \\
\hline Ala201 & Leu206 & A & 6 \\
\hline Arg211 & Pro212 & C & 2 \\
\hline Leu222 & Val223 & $\mathrm{D}$ & 2 \\
\hline Lys238 & Val242 & $\mathrm{D}$ & 5 \\
\hline His261 & Val266 & $\mathrm{D}$ & 6 \\
\hline His292 & Tyr295 & $\mathrm{D}$ & 4 \\
\hline Pro299 & Cys306 & $E$ & 8 \\
\hline Lys309 & Phe314 & $E$ & 6 \\
\hline Ser318 & Phe322 & $E$ & 5 \\
\hline Thr324 & Tyr327 & $\mathrm{D}$ & 4 \\
\hline Arg331 & Ser332 & C & 2 \\
\hline Val365 & Ala367 & A & 3 \\
\hline Thr408 & Ile410 & $\mathrm{F}$ & 3 \\
\hline Phe416 & Gly420 & $\mathrm{F}$ & 5 \\
\hline
\end{tabular}




\begin{tabular}{llll}
\hline Leu435 & Phe442 & F & 8 \\
\hline Cys471 & Glu478 & F & 8 \\
\hline Val484 & Val490 & F & 7 \\
\hline
\end{tabular}

Table 15. Helix regions found in the modeled structure of thioredoxin reductase of Babesia microti.

\begin{tabular}{llll}
\hline Start & End & Type & No.of residues \\
\hline Leu7 & Val13 & H & 7 \\
\hline Arg14 & Leu16 & G & 3 \\
\hline Lys36 & Thr45 & H & 10 \\
\hline Val48 & Ser53 & H & 6 \\
\hline Pro68 & Arg79 & H & 12 \\
\hline Gly103 & Val108 & H & 6 \\
\hline Cys110 & Leu132 & H & 23 \\
\hline Trp145 & Lys170 & H & 26 \\
\hline Thr225 & Asp228 & H & 4 \\
\hline Tyr246 & Gly257 & H & 12 \\
\hline Arg276 & Asn288 & H & 13 \\
\hline Leu340 & Val343 & H & 4 \\
\hline Gly369 & lle371 & G & 3 \\
\hline Ala379 & Phe394 & H & 16 \\
\hline Glu423 & Tyr430 & H & 8 \\
\hline Glu432 & Asn434 & G & 3 \\
\hline Leu458 & Glu462 & H & 5 \\
\hline Ala494 & Leu507 & H & 14 \\
\hline Lys511 & Leu516 & H & 6 \\
\hline Ser527 & Val533 & H & 7 \\
\hline & & & H \\
\hline
\end{tabular}

Helix-helix interactions: Helix-helix interaction is crucial in understanding the folding pattern of a protein structure especially in membrane proteins. Detail information about the obtained helix-helix interaction is provided in Table 16.

Table 16. Depiction of helix-helix interaction of the modeled protein.

\begin{tabular}{llllllll}
\hline Helices & Helix types & \multicolumn{2}{c}{ Interaction type } & \multicolumn{2}{l}{ No. interacting residues } \\
\cline { 6 - 8 } & & & & & Helix 1 & Helix 2 \\
\hline 3 & 4 & H & H & C & N & 2 & 1 \\
\hline 5 & 6 & H & H & n & n & 1 & 2 \\
\hline 5 & 8 & H & H & C & C & 4 & 3 \\
\hline 5 & 14 & H & H & I & I & 7 & 8 \\
\hline 6 & 7 & H & H & C & n & 4 & 3 \\
\hline 6 & 8 & H & H & C & I & 2 & 4 \\
\hline
\end{tabular}

\begin{tabular}{llllllll}
\hline 6 & 9 & $\mathrm{H}$ & $\mathrm{H}$ & $\mathrm{C}$ & $\mathrm{C}$ & 1 & 2 \\
\hline 6 & 14 & $\mathrm{H}$ & $\mathrm{H}$ & $\mathrm{N}$ & $\mathrm{I}$ & 1 & 1 \\
\hline 7 & 8 & $\mathrm{H}$ & $\mathrm{H}$ & $\mathrm{I}$ & $\mathrm{I}$ & 4 & 5 \\
\hline 7 & 9 & $\mathrm{H}$ & $\mathrm{H}$ & $\mathrm{n}$ & $\mathrm{C}$ & 1 & 1 \\
\hline 7 & 10 & $\mathrm{H}$ & $\mathrm{H}$ & $\mathrm{I}$ & $\mathrm{I}$ & 4 & 4 \\
\hline 7 & 14 & $\mathrm{H}$ & $\mathrm{H}$ & $\mathrm{n}$ & $\mathrm{n}$ & 1 & 1 \\
\hline 7 & 17 & $\mathrm{H}$ & $\mathrm{H}$ & $\mathrm{C}$ & $\mathrm{C}$ & 2 & 1 \\
\hline 8 & 9 & $\mathrm{H}$ & $\mathrm{H}$ & $\mathrm{I}$ & $\mathrm{C}$ & 2 & 1 \\
\hline 8 & 10 & $\mathrm{H}$ & $\mathrm{H}$ & $\mathrm{n}$ & $\mathrm{C}$ & 1 & 1 \\
\hline 9 & 10 & $\mathrm{H}$ & $\mathrm{H}$ & $\mathrm{N}$ & $\mathrm{I}$ & 2 & 3 \\
\hline 10 & 11 & $\mathrm{H}$ & $\mathrm{H}$ & $\mathrm{C}$ & $\mathrm{C}$ & 3 & 2 \\
\hline 11 & 15 & $\mathrm{H}$ & $\mathrm{H}$ & $\mathrm{n}$ & $\mathrm{n}$ & 2 & 2 \\
\hline 18 & 19 & $\mathrm{H}$ & $\mathrm{H}$ & $\mathrm{I}$ & $\mathrm{N}$ & 1 & 1 \\
\hline 18 & 20 & $\mathrm{H}$ & $\mathrm{H}$ & $\mathrm{N}$ & $\mathrm{N}$ & 2 & 1 \\
\hline 19 & 20 & $\mathrm{H}$ & $\mathrm{H}$ & $\mathrm{I}$ & $\mathrm{I}$ & 3 & 5 \\
\hline
\end{tabular}

Beta turns: Information on beta turns provides important hint about the reverse turn in a large protein molecule. Table 17 represents the observed $\beta$-turns found in the modeled protein. Abundance of proline and glycine is common in $\beta$-turns. The obtained result suggests that turn types VIII and IV are dominant for this protein. In some of cases, H-bonds were also found. The type IV turn suggests they are not perfectly defined turns whereas type VIII suggest that these turns are having-60 degree Phi (i+1), -30 degree Psi (i+1), and -120 degree Phi and Psi angle for $i+2$ residues for developing the dihedral angle.

Table 17. Beta turns observed in the modeled protein.

\begin{tabular}{llll}
\hline Turn & Sequence & Turn type & H-bond \\
\hline Met1-Arg4 & MILR & IV & Yes \\
\hline Arg4-Leu7 & RAGL & IV & VIII \\
\hline Val57-Asp60 & VKYD & IV & IV \\
\hline Lys91-His94 & KPSH & IV \\
\hline His94-Thr97 & HRGT & IV \\
\hline Arg95-Ser98 & RGTS & IV \\
\hline Lys182-Asn185 & KSAN & IV \\
\hline Ser183-Glu186 & SANE & I \\
\hline Ala184-Ile187 & ANEI & IV \\
\hline Asp191-Gly194 & DTDG & IV \\
\hline Asp219-Leu222 & DKSL & IV \\
\hline Asp228-Tyr231 & DLFY & IV \\
\hline Leu229-Leu232 & LFYL & IV \\
\hline Phe230-Asn233 & FYLN & LNND & \\
\hline Leu232-Asp235 & & \\
\hline
\end{tabular}




\begin{tabular}{|c|c|c|c|}
\hline Pro236-Thr239 & PGKT & IV & \\
\hline Leu271-Phe274 & LRGF & IV & \\
\hline Lys294-Ile297 & KYGI & IV & \\
\hline Lys304-Asp307 & KECD & IV & \\
\hline Cys306-Lys309 & CDGK & II & Yes \\
\hline Phe314-Asn317 & FSDN & IV & \\
\hline Phe322-Val325 & FDTV & VIII & \\
\hline Leu335-Met338 & LADM & IV & Yes \\
\hline Leu347-Asn350 & LSPN & 1 & Yes \\
\hline Thr360-Pro363 & TSVP & VIII & \\
\hline Val362-Val365 & VPNV & 1 & Yes \\
\hline Val372-Arg375 & VENR & II & Yes \\
\hline Met401-Ser404 & MDYS & IV & \\
\hline Thr412-Glu415 & TPYE & VIII & \\
\hline Ser444-GIn447 & SLEQ & IV & \\
\hline Arg452-Thr455 & RMKT & IV & \\
\hline Met453-Arg456 & MKTR & IV & Yes \\
\hline Thr455-Leu458 & TRHL & IV & \\
\hline Asp464-Leu467 & DTDL & VIII & \\
\hline Glu478-Thr481 & EKGT & IV & \\
\hline Lys479-Asp482 & KGTD & II' & \\
\hline Gly491-Ala494 & GPNA & IV & Yes \\
\hline Ile520-Thr523 & IHPT & VIb & \\
\hline Thr534-Ser537 & TKDS & I & \\
\hline Asp536-Glu539 & DSGE & IV & Yes \\
\hline Glu539-Val542 & ESWV & IV & \\
\hline Ser540-Ser543 & sWvS & I & \\
\hline Gly545-Gly548 & GGCG & IV & \\
\hline Gly548-Lys551 & GGGK & IV & \\
\hline
\end{tabular}

\begin{tabular}{llll}
\hline Ile410 & Thr412 & IFT & INVERSE \\
\hline Met453 & Thr455 & MKT & INVERSE \\
\hline Lys479 & Thr481 & KGT & CLASSIC \\
\hline Val533 & Lys535 & VTK & INVERSE \\
\hline
\end{tabular}

Disulphide linkage: Existence of disulphide linkage is important for proteins involved in redox associated reaction. The analysis suggested that the modeled structure is having disulphide linkage between the cysteine 105 and cysteine 110 residue number.

\section{Active site identification}

Castp server was used to predict possible binding sites of modeled structure. Out of all the sites predicted, best 10 sites were selected as shown in Figure 13. Binding sites having highest surface area and volume were selected as the most probable active sites for the modeled protein (Table 19).

Table 19. The top 10 pockets with area and volume information.

\begin{tabular}{lll}
\hline Pocket ID & Area (SA) & Volume (SA) \\
\hline 1 & 1437.150 & 1334.336 \\
\hline 2 & 517.250 & 693.072 \\
\hline 3 & 266.266 & 132.424 \\
\hline 4 & 137.962 & 81.917 \\
\hline 5 & 201.313 & 77.787 \\
\hline 7 & 127.716 & 77.102 \\
\hline 8 & 135.291 & 48.060 \\
\hline 9 & 88.826 & 42.928 \\
\hline 10 & 65.263 & 33.284 \\
\hline 11 & 82.267 & 29.309 \\
\hline
\end{tabular}

\section{Molecular docking analysis}

As mentioned in the method section, molecular docking analysis was carried out employing SwissDock docking facility. All the molecules were minimized employing CHARMM force field. The PSF, PAR files and the docking clusters were generated using the protocol provided. The parameters used are passive flexibility distance $=0.0$, wanted confs $=5000$, nbfact seval $=5000$, nbseeds $=250$, sdsteps $=100$, abnr steps $=250$, clustering radius $=2.0 \AA$ and maximum cluster size $=8$.

The target protein and the selected ligands were prepared through molecular mechanical calculations before docking exercises as per the tool protocol. The Supplementary Table 1 contains the detailed docking results of all the molecules considered. The docking analysis revealed the interactions between the ligand molecules and the target protein 
considered. The ligands are mostly auranofin derivatives as mentioned in the method section. The obtained ten best molecules along with their specific interactions are represented in Table 20. The energy values of the ligand-protein binding affinity were found between -16.51 and $-20.88 \mathrm{kcal} / \mathrm{mol}$. Some of the residues in the target proteins showed extensive affinity towards forming hydrogen bonds with the ligand molecules which are presented in "H-H bond receptor atom" column of Table 20. Interestingly, LYS 29, SER 245, CYS 110, LYS 210, SER 27 and LYS 202 showed more affinity towards the ligand molecules than other residues in the target protein. The poses of the docking are presented in Figure 14.

\section{Target protein flexibility analysis}

Molecular motion analysis provided information related to the most flexible as well as the rigid part of the target protein considered for this study. Estimated output of the flexibility of the modeled targeted protein computed through CABSflex server is provided in Figure 15. The outcome shows the deviation of the structural components of native protein as depicted in the Figure 15A. Fluctuation pattern is depicted through different color codes where maximum fluctuations are depicted towards the " $\mathrm{C}$ " and " $\mathrm{N}$ " terminal of the protein and medium range of RMSF was observed for the rest of the structural part. The contact map of ten different modes of the protein shows residue-residue fluctuations for all the amino acid residues. The RMSF fluctuation plot (Figure 15B) of all the modes shows that RMSF (root mean square fluctuation) value ranged approximately between $0 \AA$ and $8 \AA$. The analysis suggests that the movement of the protein is higher around amino acid residue number 100, 245, 450 (Figure 15C) (region represented in green and dark brown in Figure15A). The fluctuations obtained around the C-terminal and the N-terminal of the protein may be ignored considering them as free ends.

Table 20. Docking result of the top 10 molecules with specific interactions and hydrogen bonds. The "Compound ID" column contains the conformations after the ID represented with ("_,) followed by the number.

\begin{tabular}{|c|c|c|c|c|c|c|c|c|c|c|c|c|c|c|c|c|c|}
\hline $\begin{array}{l}\text { Compound } \\
\text { ID }\end{array}$ & $\begin{array}{l}\text { Clust } \\
\text { er }\end{array}$ & $\begin{array}{l}\text { Clust } \\
\text { er } \\
\text { rank }\end{array}$ & $\begin{array}{l}\text { Energy } \\
\text { (kcal/mo } \\
\text { l) }\end{array}$ & $\begin{array}{l}\mathrm{H}- \\
\text { bond } \\
\text { numbe } \\
\mathrm{r}\end{array}$ & $\begin{array}{l}\text { First } \mathrm{H}-\mathrm{H} \\
\text { bond } \\
\text { receptor } \\
\text { atom }\end{array}$ & $\begin{array}{l}\text { First } \\
\text { bond } \\
\text { atom }\end{array}$ & $\begin{array}{r}\mathrm{H}-\mathrm{I} \\
\text { ligan }\end{array}$ & & $\begin{array}{l}\text { Bond } \\
\text { length } \\
(A)\end{array}$ & $\begin{array}{l}\text { Secon } \\
\mathrm{H} \\
\text { recept } \\
\text { atom }\end{array}$ & $\begin{array}{l}\text { nd } \mathrm{H}- \\
\text { bond } \\
\text { tor }\end{array}$ & $\begin{array}{l}\text { Second } H- \\
H \quad \text { bond } \\
\text { ligand } \\
\text { atom }\end{array}$ & $\begin{array}{l}\text { Bond } \\
\text { length } \\
(\AA)\end{array}$ & $\begin{array}{l}\text { Third } \\
\text { bond } \\
\text { recepto } \\
\text { atom }\end{array}$ & $\begin{array}{l}\mathrm{H}-\mathrm{H} \\
\mathrm{or}\end{array}$ & $\begin{array}{l}\text { Third } \mathrm{H}-\mathrm{H} \\
\text { bond } \\
\text { ligand } \\
\text { atom }\end{array}$ & $\begin{array}{l}\text { Bond } \\
\text { length } \\
(A)\end{array}$ \\
\hline $\begin{array}{l}\text { CID7067547 } \\
2\end{array}$ & 7 & 1 & -20.88 & 2 & LYS 29 HZ3 & $1.5 \mathrm{LIG}$ & G 1 O5 & & 2.157 & $\begin{array}{l}\text { SER } \\
\text { OG }\end{array}$ & 27 & $\begin{array}{l}1.52 \text { LIG } 1 \\
\mathrm{H} 9\end{array}$ & 2.353 & & & & \\
\hline $\begin{array}{l}\text { CID1106849 } \\
9\end{array}$ & 0 & 2 & -20.02 & 1 & CYS 110 SG & $1.3 \mathrm{LIG}$ & G 108 & & 3.689 & & & & & & & & \\
\hline $\begin{array}{l}\text { CID5741707 } \\
2 \_1\end{array}$ & 2 & 0 & -18.61 & 2 & LYS 29 & $\begin{array}{l}1.15 \\
07\end{array}$ & LIG & 1 & 2.498 & $\begin{array}{l}\text { LYS } \\
\text { HZ1 }\end{array}$ & 202 & $\begin{array}{l}1.15 \text { LIG } 1 \\
08\end{array}$ & 2.36 & & & & \\
\hline CID88293 & 0 & 0 & -18.39 & 1 & $\begin{array}{l}\text { SER } \\
\text { HG1 }\end{array}$ & $1.1 \mathrm{LIG}$ & G $1 O 9$ & & 2.064 & & & & & & & & \\
\hline $\begin{array}{l}\text { CID5694524 } \\
4\end{array}$ & 1 & 5 & -18.37 & 1 & CYS 110 SG & $\begin{array}{l}1.14 \\
06\end{array}$ & LIG & 1 & 3.846 & & & & & & & & \\
\hline $\begin{array}{l}\text { CID1090457 } \\
\text { 8_1 }\end{array}$ & 4 & 0 & -17.54 & 1 & CYS 110 SG & $\begin{array}{l}1.30 \\
08\end{array}$ & LIG & 1 & 3.294 & & & & & & & & \\
\hline $\begin{array}{l}\text { CID153711_ } \\
3\end{array}$ & 2 & 5 & -17.44 & 2 & CYS 110 SG & $\begin{array}{l}1.22 \\
08\end{array}$ & LIG & 1 & 3.298 & $\begin{array}{l}\text { CYS } \\
\text { SG }\end{array}$ & 110 & $\begin{array}{l}1.22 \text { LIG } 1 \\
07\end{array}$ & 3.711 & & & & \\
\hline $\begin{array}{l}\text { CID1110057 } \\
7 \_1\end{array}$ & 1 & 0 & -17.40 & & & & & & & & & & & & & & \\
\hline $\begin{array}{l}\text { CID153711_ } \\
12\end{array}$ & 8 & 0 & -17.00 & 1 & LYS 202 HZ3 & $\begin{array}{l}1.50 \\
07\end{array}$ & LIG & 1 & 2.159 & & & & & & & & \\
\hline CID153711 & 14 & 0 & -16.51 & 3 & LYS 29 & $\begin{array}{l}1.92 \\
07\end{array}$ & LIG & 1 & 2.378 & $\begin{array}{l}\text { LYS } \\
\text { HZ1 }\end{array}$ & 202 & $\begin{array}{l}1.92 \text { LIG } 1 \\
\text { O9 }\end{array}$ & 2.001 & $\begin{array}{l}\text { LYS } \\
\text { HZ3 }\end{array}$ & 202 & $\begin{array}{l}1.92 \text { LIG } 1 \\
01\end{array}$ & 2.17 \\
\hline
\end{tabular}

\section{Conclusion}

Lack of vaccine for combating human Babesiosis also implores us to search for novel drug targets and development of new, safe and effective chemotherapeutic agents. The infection is caused by the intra-erythrocytic parasitic genus Babesia. The transmission cycle of this parasite is maintained in both vertebrate and non-vertebrate hosts and the parasite infects a wide range of vertebrates. Across various geographical regions, human Babesiosis is caused by different parasitic species such as B. microti, WA1 piroplasm, B. divergens etc.
Thus, it is cumbersome to develop a single potent and effective vaccine for effective prevention or control of human babesiosis. Several research efforts have been made to develop and crosscheck the possibility of a recombinant vaccine against different species of Babesia, such as Babesia bovis, B. microti etc. None of these efforts have been successful in providing complete solution in this regard. The complex process of host cell invasion of this parasite should be further explored to target several molecular events and multiple stages for vaccine design and development. 
An effective inhibitor which may act against almost all the species would be a great support to the existing treatment as we cannot ignore the lethal consequences of the infection in several cases. Keeping in view the possibility of relapse and the emergence of atovaquone resistant strains after treatment, there is a dire need for exploring new drug targets and drugs.

In the current study, we developed a reasonably good high quality three dimensional structure of thioredoxin reductase of B. microti using homology modeling approach. The good quality of refined model was obtained using the state-of-the-art computational methodology and the outcome of the analysis was confirmed by using standard structure validation tools. As no experimentally determined structure of the considered enzyme is available, we believe that this model will aid in initiating drug discovery exercises and studies based on structural and functional insights obtained in this study. The docking analysis with derivatives of inhibitor auranofin which has already shown huge potential against an array of gram positive bacteria may pave a way towards procuring a series of excellent and effective medication against the pathogen.

\section{Acknowledgement}

Neelima Arora thanks University grants Commission for Postdoctoral fellowship.

\section{References}

1. Lobo CA, Cursino-Santos JR, Alhassan A, Rodrigues M. Babesia: an emerging infectious threat in transfusion medicine. Knoll LJ PLoS Pathogens 2013; 9: 1003387.

2. Skrabalo Z, Deanovic Z. Piroplasmosis in man; report of a case. Doc Med Geogr Trop 1957; 9: 11-16.

3. Western KA, Benson GD, Gleason NN, Healy GR, Schultz MG. Babesiosis in a Massachusetts resident. N Engl J Med 1970; 283: 854-856.

4. Esernio-Jenssen D, Scimeca PG, Benach JL, Tenenbaum MJ. Transplacental/perinatal babesiosis. J Pediatr 1987; 110: 570-572.

5. Leiby DA1. Babesiosis and blood transfusion: flying under the radar. Vox Sang 2006; 90: 157-165.

6. Kjemtrup AM, Conrad PA. Human babesiosis: an emerging tick-borne disease. Int J Parasitol 2000; 30: 1323-1337.

7. Regner EL, Thompson CS, Iglesias AA, Guerrero SA, Arias DG.Biochemical characterization of thioredoxin reductase from Babesia microti. Biochimie 2014, 99: 44-53.

8. Banerjee AK, Arora N, Murty US. Structural model of the Plasmodium falciparum thioredoxin reductase: a novel target for antimalarial drugs. J Vector Borne Dis 2009; 46: 171 .

9. Banerjee AK, Arora N, Murty US. Analyzing a potential drug target N-Myristoyltransferase of Plasmodium falciparum through in silico approaches. J Glob Infect Dis 2012; 4: 43.
10. Arora N, Banerjee AK, Murty US. In silico characterization of Shikimate Kinase of Shigella flexneri: a potential drug target. Interdiscipl Sci Comp Life Sci 2010; 2: 280-290.

11. Arora N, Banerjee AK, Murty US. Homology model of 2C-methyl-d-erythritol 2, 4-cyclodiphosphate (MECP) synthase of Plasmodium falciparum 3D7. Electron J Biol 2010; 6: 52-57.

12. Banerjee AK, Arora N, Murty US. Aspartate carbamoyltransferase of Plasmodium falciparum as a potential drug target for designing anti-malarial chemotherapeutic agents. Med Chem Res 2012; 21: 2480-2493.

13. Duddela S, Sekhar PN, Padmavati GV, Banerjee AK, Murty US. Probing the structure of human glucose transporter 2 and analysis of protein ligand interactions. Med Chem Res 2010; 19: 836-853.

14. Arora N, Chari UV, Banerjee AK, Murty US. A computational approach to explore Plasmodium falciparum 3D7 chorismate synthase. Intern J Genom Proteom 2007; 3.

15. Banerjee AK, Murty US. Extracting the significant descriptors by 2D QSAR and docking efficiency of NRTI drugs: a molecular modeling approach. Intern J Genom Proteom 2007; 2.

16. Arora N, Narasu ML, Banerjee AK. Shikimate kinase of Yersinia pestis: a sequence, structural and functional analysis. Int J Biomed Data Min 2016; 5: 2.

17. Shinde SP, Banerjee AK, Arora N, Murty US, Sripathi VR, Pal-Bhadra M, Bhadra U. Computational approach for elucidating interactions of cross-species miRNAs and their targets in Flaviviruses. J Vector Borne Dis 2015; 52: 11.

18. Gasteiger E, Hoogland C, Gattiker A, Duvaud S, Wilkins MR, Appel, RD. Protein identification and analysis tools on the ExPASy server. Proteomics Protocols Handbook Humana Press 2005.

19. Kurgan LA, Razib AA, Aghakhani S, Dick S, Mizianty MJ, Jahandideh S. CRYSTALP2: sequence-based protein crystallization propensity prediction. BMC Struct Biol 2009; 9: 50.

20. Slabinski L, Jaroszewski L, Rychlewski L, Wilson IA, Lesley SA, Godzik A. XtalPred: a web server for prediction of protein crystallizability. Bioinformatics 2007; 23: 3403-3405.

21. Timothy LB, Charles E. Fitting a mixture model by expectation maximization to discover motifs in biopolymers. Proc Sec Int Conf Intel Sys Mol Biol AAAI Press Menlo Park California 1994; 28-36.

22. Berezin C, Glaser F, Rosenberg J, Paz I, Pupko T, Fariselli P, Casadio R, Ben-Tal N. ConSeq: the identification of functionally and structurally important residues in protein sequences. Bioinformatics 2004; 20: 1322-1324

23. Ashkenazy H, Abadi S, Martz E, Chay O, Mayrose I, Pupko T, Ben-Tal N. ConSurf 2016: an improved 
methodology to estimate and visualize evolutionary conservation in macromolecules. Nucl Acids Res 2016.

24. Combet C, Blanchet C, Geourjon C, Deleage G. NPS@: network protein sequence analysis. Trends Biochem Sci 2000; 25: 147-150.

25. Deleage G, Roux B. An algorithm for protein secondary structure prediction based on class prediction. Protein Eng 1987; 1: 289-294.

26. King RD, Sternberg MJ. Identification and application of the concepts important for accurate and reliable protein secondary structure prediction. Protein Sci 1996; 5: 2298-2310.

27. Garnier J, Gibrat JF, Robson B. GOR method for predicting protein secondary structure from amino acid sequence. Methods Enzymol 1996; 266: 540-553.

28. Guermeur Y, Geourjon C, Gallinari P, Deleage G. Improved performance in protein secondary structure prediction by inhomogeneous score combination. Bioinformatics 1999; 15: 413-421.

29. Rost B, Sander C. Prediction of protein secondary structure at better than 70\% accuracy. J Mol Biol 1993; 232: 584-599.

30. Frishman D, Argos P. Incorporation of non-local interactions in protein secondary structure prediction from the amino acid sequence. Protein Eng 1996; 9: 133-142.

31. Geourjon C, Deleage G. SOPMA: significant improvements in protein secondary structure prediction by consensus prediction from multiple alignments. Comput Appl Biosci 1995; 11: 681-684.

32. Levin JM, Robson B, Garnier J. An algorithm for secondary structure determination in proteins based on sequence similarity. FEBS Lett 1986; 205: 303-308.

33. Deleage G, Blanchet C, Geourjon C. Protein structure prediction: implications for the biologist. Biochimie 1997; 79: 681-686.

34. Linding R, Jensen LJ, Diella F, Bork P, Gibson TJ, Russell RB. Protein disorder prediction: implications for structural proteomics. Structure 2003; 11: 1453-1459.

35. Linding R, Russell RB, Neduva V, Gibson TJ. GlobPlot: exploring protein sequences for globularity and disorder. Nucleic Acids Res 2003; 31: 3701-3708.

36. Yang ZR, Thomson R, McNeil P, Esnouf RM. RONN: the bio-basis function neural network technique applied to the detection of natively disordered regions in proteins. Bioinformatics 2005; 21: 3369-3376.

37. Ishida T, Kinoshita K. PrDOS: prediction of disordered protein regions from amino acid sequence. Nucleic Acids Res 2007; 35: 460-464.

38. Biasini M, Bienert S, Waterhouse A, Arnold K, Studer G, Schmidt T, Kiefer F, Cassarino TG, Bertoni M, Bordoli L, Schwede T. SWISS-MODEL: modelling protein tertiary and quaternary structure using evolutionary information. Nucl Acids Res 2014; 42: 252-258.

39. Angelucci F, Dimastrogiovanni D, Boumis G, Brunori M,
Miele AE, Saccoccia F, Bellelli A. Mapping the catalytic cycle of Schistosoma mansoni thioredoxin glutathione reductase by X-ray crystallography. J Biol Chem 2010; 285: 32557-32567.

40. Sali A, Blundell TL. Comparative protein modelling by satisfaction of spatial restraints. J Mol Biol 1993; 234: 779-815.

41. Humphrey W, Dalke A, Schulten K. VMD: visual molecular dynamics. J Mol Graph 1996; 14: 27-28, 33-38.

42. Pettersen EF, Goddard TD, Huang CC, Couch GS, Greenblatt DM, Meng EC, Ferrin TE. UCSF Chimera-a visualization system for exploratory research and analysis. J Comp Chem 2004; 25: 1605-1612.

43. Lovell SC, Davis IW, Arendall WB, de Bakker PI, Word JM, Prisant MG, Richardson JS, Richardson DC. Structure validation by Calpha geometry: phi, psi and Cbeta deviation. Proteins 2003; 50: 437-450.

44. Colovos C, Yeates TO. Verification of protein structures: patterns of nonbonded atomic interactions. Protein Sci 1993; 2: 1511-1519.

45. Laskowski RA. PDBsum: summaries and analyses of PDB structures. Nucleic Acids Res 2001; 29: 221-222.

46. Dundas J, Ouyang Z, Tseng J, Binkowski A, Turpaz Y, Liang J. CASTp: computed atlas of surface topography of proteins with structural and topographical mapping of functionally annotated residues. Nucleic Acids Res 2006; 34: 116-118.

47. Harbut MB, Vilcheze C, Luo X, Hensler ME, Guo H, Yang B, Chatterjee AK, Nizet V, Jacobs WR, Schultz PG, Wang F. Auranofin exerts broad-spectrum bactericidal activities by targeting thiol-redox homeostasis. Proc Nat Acad Sci 2015; 112: 4453-4458.

48. Grosdidier A, Zoete V, Michielin O. SwissDock, a protein-small molecule docking web service based on EADock DSS. Nucleic Acids Res 2011; 39: W270-277.

49. Kuriata A, Gierut AM, Oleniecki T, Ciemny MP, Kolinski A, Kurcinski M, Kmiecik S. CABS-flex 2.0: a web server for fast simulations of flexibility of protein structures. Nucleic Acids Res 2018.

50. Hirt RP, Muller S, Embley TM, Coombs GH. The diversity and evolution of thioredoxin reductase: new perspectives. Trends Parasitol 2002; 18: 302-308.

51. Xiong $\mathrm{H}$, Buckwalter BL, Shieh HM, Hecht $\mathrm{MH}$. Periodicity of polar and nonpolar amino acids is the major determinant of secondary structure in self-assembling oligomeric peptides. Proc Nat Acad Sci 1995 3; 92: 6349-6353.

52. Wiederstein M, Sippl M. ProSA-web: interactive web service for the recognition of errors in three-dimensional structures of proteins. Nucleic Acids Res 2007; 35: 407-410.

53. Melo F, Feytmans E. Assessing protein structures with a non-local atomic interaction energy. J Mol Biol 1998; 277: 1141-1152. 


\section{*Correspondence to}

\section{Neelima Arora}

Centre for Biotechnology (CBT)

Institute of Science and Technology (Autonomous)

Jawaharlal Nehru Technological University Hyderabad

Telangana

India 